also correctly predicts the breakdown strength of silicon dioxide filmsanother indication that these measurements should rapidly find practical application.

\section{Mobility and Lifetime}

Surprisingly, mobility and lifetime are lower in crystalline silica and, although it is difficult to control the incorporation of impurities during the growth of quartz crystals, a correlation of carrier lifetime and mobility with degree of impurity of crystal seems to exist. For example, Hughes finds that lithiumdoped synthetic quartz has a higher mobility-lifetime product than the nondoped variety, whereas the synthetic fused silica samples, always much more pure than the flux-grown crystals, typically have twice the carrier lifetime of the crystals and well over twenty times the mobility value. Although the reduced mobility might suggest trapping phenomena as the cause, the mobility exhibits little temperature dependence. Thus, the more likely explanation is some form of impurity scattering, as confirmed in semiconductors. The field dependence of the radiation-induced conductivity again suggests LO phonon interaction as the limiting effect, since the drift velocity saturates at about the levels predicted by Thornber and Feynman (Phys. Rev., B1, 4099; 1970), around $10^{7} \mathrm{~cm} \mathrm{~s}^{-1}$.

The question, then, is why an amorphous solid should possess such high mobility-indicating a mean free path of about $40 \AA$-when, according to most theories of the amorphous state, the mean free path should be of atomic dimensions, on account of the presence of localised states induced by the presence of disorder (see, for example, the studies on amorphous silicon by Spear and Le Comber, J. Non-cryst. Solids, $8-10,727 ; 1972$ ). This would seem to confirm the X-ray evidence (Konnert, Karle and Ferguson, Science, N.Y., 179, 177 ; 1973) that the short-range order in fused silica is very good, the only deviation from order being some variation in $\mathrm{Si}-\mathrm{O}-\mathrm{Si}$ bond angles. This probably means that there is not a large amount of bond strain in the atomic network, therefore the same wide distribution in binding energies found in many amorphous solids does not exist. This could well lead to a major reduction of the 'tail' of localised states normally required to explain the transport and optical properties of compounds like the chalcogenide glasses.

Certainly, the reflectance spectra of fused silica and quartz look astonishingly alike (Phillipp, J. Phys. Chem. Solids, 32, 1935; 1971) and some might say that the high mobility suggests that silica borders on the microcrystalline. But just as melting produces no strong discontinuity in the conductivity of good conductors (see, for example, Adler, Crit. Rev. solid state Sci., 2, 317; 1971), it may be that electron transport continues to be efficient whenever short range order persists and thus so far the picture of fused silica as an amorphous solid remains. It should also be said that Hughes finds that holes seem to be very firmly lattice trapped and do not contribute at all to the photoconduction. This confirms most previous findings in thin-film silica and lends support to the current theories of spacecharge build-up in these materials (see, for example, Zaininger and HolmesSiedle, $R C A$ Rev., 28 (2), 208; 1967).

\section{Implications}

One general conclusion is that it may take as much (or more) trouble and time to obtain insulator crystals free of troublesome impurities as it did for semiconductors especially since, at the moment, there is not as strong a technological motivation for producing them. For those concerned with controlling radiation-induced conductivity (reactor designers and so on) manipulation of impurity scattering may, however, provide a useful tool for reducing unwanted conductivity. Second, one can echo a conclusion of Revesz (J. Non-cryst. Solids, 7, 435; 1972) that the amorphous oxides, nitrides and related glasses might provide a good medium for the basic study of the amorphous state because they are disordered only in the mildest way possible. Third, low field conduction work has received encouragement from these findings, which have tied together and strengthened some previously intriguing but hardly demonstrable hypotheses on transport in insulators and, incidentally, have annihilated at least one earlier theory of field dependence of mobility in silica (Onnasch, Phys. stat. sol., 38, 579; 1970).

\section{PALAEONTOLOGY}

\section{Fossil Diversity}

IT is widely acknowledged tectonics has had a revitalising effect on many fields of earth science, and nowhere is this more true than in palaeobiogeography, which is the name given to the study of fossil distributions in time and space. Abundant evidence of the burgeoning interest in this subject is provided by the numerous papers recently published in the Atlas of Palaeobiogeography (edit. by A. Hallam, Elsevier, 1973), and in two conference symposia, Organisms and Continents Through Time (edit. by N. F. Hughes, Paleont. Ass. Spec. Paper 12, 1973) and Implications of Continental Drift to the Earth Sciences, vol. 1 (edit. by D. H.

\title{
Rock of Grenville Age found on Rockall Bank
}

GEOPHYSICAL evidence suggests that the Rockall Plateau (and thus the Rockall Bank which forms part of it) may be a microcontinent isolated during one of the phases of spreading in the North Atlantic region. Until recently, however, geological evidence for a continental basement structure in the form of granitic or metamorphic rocks on the plateau was not entirely convincing, because, although several dredge hauls had been carried out in the vicinity of the plateau, most of the recovered samples could not be interpreted unambiguously. Moreover, further ambiguity was introduced by the presence of iceberg plough marks around the Rockall bank and evidence of ice-rafted deposition.

This equivocal situation was resolved earlier this year when Roberts et al. (Nature phys. Sci., 244, 21; 1973) reported the results of drilling two outcrops about $100 \mathrm{~km}$ apart in the southern section of the Rockall Bank. Granulite facies metamorphic rocks were found at both sites. In one case the hornblende in the drill core (acid granulite) was dated at $1566 \pm 33$ million years (Loxfordian) and the whole rock at $1670+$ 24 m.y. Thus the presence of continental rocks underlying the Rockall Bank was confirmed, suggesting, by ex- tension, that the whole Rockall Plateau may indeed be a microcontinent.

But Roberts and his colleagues also proposed that rocks of Grenville age may occur on the southern section of the Rockall Bank - a prediction arrived at by considering the pre-drift reconstruction of the North Atlantic Ocean in the light of the new Loxfordian age. This prediction has now been confirmed by Miller, Roberts and Matthews who report their discovery in Nature Physical Science next Monday (November 26). The rock concerned, an andesineorthopyroxene-biotite-quartz granulite, is that obtained previously by Roberts and his colleagues at the southernmost of their two sites on the southern section of the Rockall Bank.

This age obtained $(987 \pm 5$ m.y.) is the first Grenville age found within the British Isles or west of the Caledonian Front in Europe and suggests that the Grenville Front crosses the southern section of the Rockall Bank, although confirmatory results from other rock samples will be required before certainty can be claimed. In the meantime, however, Miller and his colleagues make a further prediction-that rocks of Grenville age may also underlie parts of the Porcupine Bank or the continental shelf off Northern Ireland. 